\title{
INFÂNCIAS (IN) VISIBILIZADAS: REFLEXÕES SOBRE A CRIANÇA NEGRA NA HISTÓRIA DE VILHENA-RO
}

\author{
CHILDREN INVISIBILIZED: REFLECTIONS ON THE BLACK CHILD IN THE \\ HISTORY OF VILHENA-RO
}

\author{
Josiane Brolo Rohden (UNIR) -josiane.rohden@unir.br \\ Daniella Cristina dos Santos de Souza Batista (UNIR) - daniluna04@gmail.com \\ Jaqueline Souza Silva (UNIR) - sjacksilvaaa@gmail.com \\ Vera Lucia Aquino Boing (UNIR) - vera-sanboing@hotmail.com \\ Vanessa de Oliveira da Silva (UNIR) - vanessayasmimoliveira@gmail.com
}

RESUMO: Esse trabalho busca promover a visibilidade da criança negra no cotidiano da história da Educação de Vilhena - RO, entre os anos de 1960 a 1980. Sabe-se que na história, as crianças não receberam a visibilidade merecida por seus papeis sociais, culturais, e nesse contexto, as crianças negras são praticamente ainda mais invisibilizadas. Poucos registros contam com a presença de crianças não brancas durante o processo de colonização e migração de Vilhena, como se não houvesse a presença de povos de diferentes etnias. A história contada é branca, sem pretos, pardos, sem os povos originários da floresta. Como se trata de uma pesquisa que também envolve o tema da diversidade cultural, essa investigação busca contribuir para a discussão de ruptura do modelo eurocêntrico na educação e sucessivamente na análise histórica e social da participação do afrodescendente na construção de uma educação multicultural na escola brasileira. A execução metodológica no âmbito da Nova História Cultural (NHC) se utiliza de fontes documentais e fotografias históricas de infâncias dos migrantes que vivenciaram tal experiência no cenário em estudo.

Palavras-chave: Infância Negra. Migração. Vilhena-RO.

ABSTRACT: This work seeks to promote the visibility of black children in the daily history of Education in Vilhena-RO, between the years 1960 and 1980. It is known that in history, children have not received the visibility deserved by their social, cultural roles, and in this context, black children are practically even more invisible. Few records have the presence of non-white children during the process of colonization and migration of Vilhena, as if there were no people of different ethnicities. The story told is white, without blacks, browns, without the native peoples of the forest. As this is a research that also involves the theme of cultural diversity, this investigation seeks to contribute to the discussion of the rupture of the Eurocentric model in education and successively in the historical and social analysis of the participation of people of African descent in the construction of a multicultural education in the Brazilian school. The methodological execution within the scope of the New Cultural History (NHC) uses documentary sources and historical photographs of the migrants' childhoods who had experienced such an experience in the study scenario.

Keywords: Black Childhood. Migration. Vilhena-RO. 


\section{INTRODUÇÃO}

Esse trabalho busca promover a visibilidade da criança negra no cotidiano da história da Educação de Vilhena entre os anos de 1960 a 1980, período marcado pelo intenso povoamento na região norte do país.

Sabe-se que na história, as crianças não receberam a visibilidade merecida por seus papeis sociais, culturais, e nesse cenário, as crianças negras são praticamente ainda mais invisibilizadas. Poucos registros contam com a presença de pessoas/crianças não brancas durante o processo de colonização e migração de Vilhena, como se não houvesse a presença de povos de outras etnias. A história contada é branca, sem pretos, pardos, sem os povos originários da floresta.

A cidade de Vilhena tem sua formação relacionada aos trabalhos telegráficos realizados por Marechal Cândido Rondon, em igı, no entanto, em meados do século XX, início de 196o se inicia o processo de ocupação territorial por migrantes trazidos em sua maioria pela atração de terras, contudo, sua história nos revela um processo de migração branca, na sua maioria sulistas, com traços culturais europeus. Entretanto, sabe-se que a cidade é formada também por outras culturas, outros povos, desde a sua formação, o que não é contado pela História Oficial, projetando a ideia entre gerações de uma cultura única, absoluta.

A pesquisa propõe desmistificar tal ideia no que se diz respeito, em especial, à presença infantil negra, a cultura produzida, as tradições presentes no cotidiano da história de Vilhena.

Contudo, intenta-se analisar o espaço ocupado pela criança negra no cenário social que se formava a partir de fontes históricas como registros escolares, fotografias, documentos e também a partir das memórias de sujeitos participantes desta pesquisa.

Pretende-se trabalhar a presente pesquisa na perspectiva da Nova História Cultural (NHC), constituindo desta forma, uma história que se detém nas particularidades, nas culturas de modo mais pormenorizadas. Nesse sentido, a partir da perspectiva da NHC, a pesquisa, se mostra proveitosa ao abrir possibilidades de abordagem de uma história de colonização "recente" do estado de Rondônia, repleta de significantes que a história positivista não permite.

Diante disso, no destaque desta pesquisa no âmbito da NHC, buscaremos em Certeau (1998) enfatizar a cultura produzida pelo "homem comum" e, a história dos "heróis sem nome", no movimento do pensar sobre a invenção e reinvenção do cotidiano dos sujeitos envolvidos nesta pesquisa de cunho historiográfico.

A relevância desta pesquisa, se justifica a priori, na possibilidade de perceber, a partir dos vestígios deixados pela história, a presença da criança negra e a cultura produzida pela mesma naquele momento de migração e colonização, além de contribuir para com o conhecimento de como 
se compunha o cotidiano dessa criança. E, em especial, se configura a possibilidade de analisar a História da Infância, produtora de uma cultura específica, munida de táticas de subversão, mesmo diante de imposições e estratégias vindas de um lugar de poder, neste caso, a escola, a família, a igreja, a sociedade (Cf. CERTEAU, 1998).

Também, como se trata de uma pesquisa que envolve o tema da diversidade cultural, essa investigação busca contribuir para a discussão de ruptura do modelo eurocêntrico no ensino e sucessivamente na análise histórica e social da participação do afrodescendente na construção de uma educação multicultural na escola brasileira.

Contudo, fundamenta seu valor, por contemplar os estudos de uma parte geográfica de Rondônia ainda não muito conhecida pelos próprios cidadãos rondonienses, e, então, a finalidade da projeção desta pesquisa infere na possibilidade de apresentar os diferentes costumes, tradições, hábitos, a cultura que constitui o cotidiano da vida de muitas pessoas que vivem neste estado, e, que não tiveram suas histórias contadas pela História Oficial e pouco aparecem nos livros didáticos no que se refere à história "recente" de migração/colonização territorial do estado.

Finalmente, trata-se de uma pesquisa onde o conhecimento será construído, elaborado, desfeito, reconstruído e, especialmente, integrado multidisciplinarmente na qual ciência, técnica e cultura entrecruzam-se, de maneira a produzir os mais diferentes saberes e conhecimentos (Cf. BENJAMIN, 1987).

\section{A constituição de Vilhena-RO: movimentos do processo migratório na Amazônia}

A cidade de Vilhena está localizada na região sul do estado de Rondônia, tornou-se município pela Lei de no 6.448 de in de Outubro de 1977. A escolha do nome do local, ainda feita por Marechal Rondon, se dera em homenagem ao Organizador da Carta Telegráfica Pública, Álvaro Coutinho de Melo Vilhena, durante a chamada "Missão Rondon".

As histórias vividas e relatadas em documentos escritos de Marechal Rondon e de Roquette Pinto que juntos faziam parte de tal missão em meados de I9I2, relatam que tal expedição foi responsável por grande parte do desenvolvimento da região amazônica e da integração nacional do país.

Apresentamos uma fotografia onde aparecem Marechal Cândido Rondon e alguns dos membros que constituíam tal Missão, qual fez de Rondônia o que futuramente viria a ser um estado, cujo nome faz referência ao Chefe desta expedição. 
Figura r: Imagem de parte dos integrantes da Expedição Rondon, I9I4.

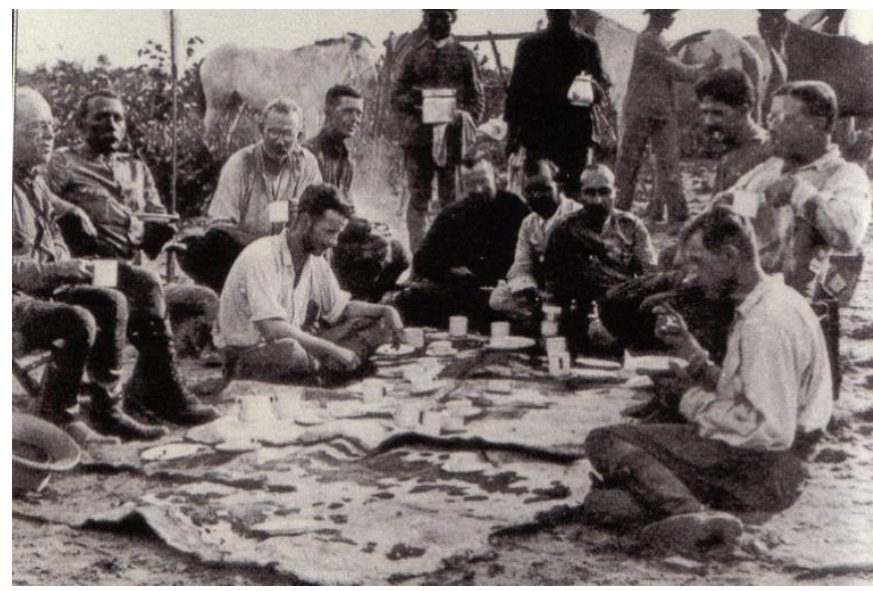

Fonte: Site Rondônia Agora (2020).

De acordo com Rohden e Martins (2014), pontua-se que de 1900 a 1906, Rondon, nomeado chefe da Comissão Construtora de Linhas Telegráficas no Estado de Mato Grosso, iniciou, a construção das linhas que ligariam a capital ao sul do Estado. Ao longo do desenvolvimento do trabalho, garantiu as terras aos índios e protegeu os povos Bororo, Terena, Ofayé e Kadiwéu. Em 1904, o chefe da Comissão encontrou grandes dificuldades para fixar postes no Pantanal, assim, grupos indígenas, especialmente os Bororos e os Paresi, integram-se como aliados fundamentais no trabalho de campo da Missão ao abrir picadas e revelar os mistérios da mata.

Para tanto, ainda de acordo com as autoras supracitadas (idem), no início da segunda metade do século XX, com a implantação das linhas telegráficas realizadas pela Comissão Rondon, que uniria a região Norte ao restante do país, o estado de Rondônia passou a receber um grande número de migrantes quais saiam na sua maioria da região sul do Brasil em busca de melhores condições de vida na região norte. O que favoreceu este processo de migração foi à construção da rodovia BR-29, atual BR-364. Desta forma, pode-se dizer que a região foi marcada por dois pontos fundamentais na história de sua ocupação, a passagem das linhas telegráficas e a construção da rodovia citada.

Devido ser um município que faz divisa com o Mato Grosso, Vilhena, tornou-se um ponto de chegada para muitos migrantes aventureiros. A região onde está localizada a cidade ficou conhecida como "Portal Amazônico de Boas-vindas" e o "Cone sul do Estado" a vários migrantes que desta terra pretendiam alcançar o sonhado "Eldorado".

Em 1960, um grande acontecimento impulsionaria Vilhena com a visita do Presidente Juscelino Kubitschek - a abertura da BR- 029, atual BR-364. A região então, passa a atrair pessoas de 
diversas localizações do país e, logo ocupada, com a pouca infraestrutura local. Como explica Gomes (2012, p.173):

As cidades, em suas origens eram compostas por casas e barracões de madeira; era uma raridade alvenaria. A paisagem era tomada por serrarias, botecos, máquinas de beneficiamentos de grãos e serialistas comerciantes de produtos agrícolas como arroz, milho, feijão e café. Todas as casas possuíam pregos pelo lado de dentro que serviam como "cabideiros"; nas cabeceiras das camas mais um prego, esse era para o "soro" aplicado nos pacientes que comumente contraiam malária, doenças bastante comum que assolou todas as regiões do território e mais tarde do Estado de Rondônia.

A cidade chamava a atenção devido à diversidade natural, com várias planícies, campos verdejantes, clima tropical, altas árvores nativas, águas claras e rios caudalosos que rodeava a cidade como o Rio Vermelho, Barão do Melgaço, Piracolina e Pires de Sá, constituíam um cenário atraente para um futuro mais promissor àqueles que no local chegavam, ensejavam um pedaço de terra, era um lugar que no imaginário social se fazia cheio de vida e esperança.

Muitos sonhavam e de certa forma foram induzidos a sonhar com a marcante propaganda da época, que: "[...] a terra era tão boa que pé de milho em Colorado-RO produzia cada um até sete espigas; pé de quiabo crescia tanto que as pessoas subiam para colher, maracujá dava de quilos; abóboras e mandiocas gigantes [...]" (GOMES, 2012, p.174).

Essa era a imagem que muitos migrantes tinham do novo estado e assim, de Vilhena. Entretanto, a realidade da comunidade que se formava estava um tanto distante das falas e dos sonhos, à terra precisava ser trabalhada, adubada, havia muitas matas fechadas que até então tomavam conta dos perímetros urbanos. As estradas ainda estavam em abertura, o sofrimento para se chegar até o local era grande, muitas famílias que chegavam em grandes quantidades, vinham transportados por caminhões de "pau de arara" e pelas companhias de ônibus que iniciava seus trabalhos no estado.

Brasil (2000) destaca que a chegada desses migrantes à região, marcava-se pela extrema precariedade. As estradas não tinham pavimentação, era de terra, coberta por poeira durante o verão e na temporada de inverno chovia muito e, as estradas ficavam ainda mais precárias, por diversas vezes, era necessário parar e montar acampamentos a beira das mesmas, as crianças eram transportadas junto aos adultos e na maioria das vezes tratadas sem a necessária atenção e cuidados.

\footnotetext{
${ }^{1}$ Adaptações de meios de transportes precárias para transportar pessoas.
} 
Contudo, uma miscigenação de culturas foi tomando conta da região e a migração era constante, não demorou muito e intensificou a chegada de todos os lados de aventureiros, garimpeiros e colonos e outros a procura de terras e riquezas.

A esfera de migração foi muito forte por parte dos sulistas e dos nordestinos, as geadas que acabavam com os campos do sul traziam esses povos à procura de clima tropical para plantar e colher, os nordestinos com a mão-de-obra barata e à procura de terras férteis também ocuparam grande parte da região.

Muitos que chegavam, encontraram inúmeras dificuldades, muitas famílias foram vítimas do "descaso governamental" como relata Gomes (2000), com muitas falhas no processo de colonização e integração dos colonos, a dificuldade de adaptação ao clima tropical das florestas, a fauna, a flora e a malária assolava a muitos, levando inúmeros à morte. A ausência de órgãos fiscalizadores deixou de proteger as florestas, comprometendo diversas espécies de árvores, plantas e animais.

Durante esse período de colonização da região, diversas políticas foram adotadas pelo Governo Militar. Muitas famílias que possuíam somente o dinheiro da venda de suas propriedades anteriores, ao investirem demasiadamente na colonização das terras apropriadas, começaram a passar por dificuldades, pois, à terra necessitava de cuidados para o cultivo.

Os pequenos agricultores se endividavam e sem as condições básicas para se manter, vendiam suas propriedades ocupadas por preços baixíssimos para grandes fazendeiros que se expandiam cada vez mais, alguns conquistados com sucesso próprio, porém, outros com o suor de pequenos agricultores. Com as terras já desmatadas e o solo beneficiado de alguns preparos se tornava ótima a negociação. Contudo, as famílias gradualmente foram se dissipando e vários colonos passaram a buscar terras em outras localidades, vivendo de muito trabalho e de muita dificuldade financeira.

De acordo com Perdigão e Bassegio (1992, p.II4):

Os trabalhadores são vítimas do modelo de colonização de Rondônia, pois os projetos de assentamento são executados normalmente entre grandes fazendas, e as terras férteis ficam retidas com os grandes fazendeiros, ou são consideradas reservas florestais. As terras amarelas, utilizadas para o plantio de árvores permanentes ou pastos, foram distribuídas para as famílias de lavradores. Estas famílias de migrantes trabalham durante, por vários dias, na derrubada da mata. Alguns fazem percursos de 20 a $40 \mathrm{~km}$ para chegar em seus lotes com o "Cacaio" nas costas enfrentando sol quente, picadas, doenças e todo tipo de sofrimento [...]. Como se nota, a terra tem sido o elemento básico de separação máxima das classes sociais fundamentais. Para o INCRA, faltavam verbas e a demanda é maior que a oferta. A exploração do capital manifesta-se para os migrantes trabalhadores "semterra", impondo formas de serviç,os em regime de escravidão [...]. 
Nesse contexto, de acordo com os estudos de Martins (2017) o garimpo, a plantação de milho, o arroz, a mandioca e o feijão mantinham a maior parte da movimentação dos comércios. A pequena cidade de Vilhena foi se desenvolvendo e, consequentemente a necessidade de implantação de escolas, comércios variados, bancos e outros, se fortaleciam no novo vilarejo.

Neste sentido, tal trajetória migratória, trouxe consigo a mistura de raças, costumes, culturas, sentimentos, conquistas, coragem, derramamento de sangue e, muito desejo de "progresso", qual custaria todo um processo de desmatamento de nossas florestas, extinção de espécies da fauna e flora, e até mesmo extermínio de muitos povos nativos (Cf. MARTINS, 2017).

Todo esse processo contou também com a presença da mulher, das crianças, porém, esses praticamente não aparecem nos feitos da história. Assim, esse trabalho pretende dar visibilidade em especial a participação da infância, com um olhar singularizado para a criança negra. Trata-se de uma pesquisa que dá os primeiros passos na intenção da "escrita da história" (Cf. CERTEAU, 1982).

\section{Infância em Vilhena e a História Oficial Branca}

Enquanto cunho historiográfico, esta pesquisa ancorada nos estudos da Nova História Cultural, faz emergir uma história não contada pela História Oficial. Desta forma, vale ressaltar que no lócus investigado, a infância não é assunto tratado historicamente. Elas (as crianças) estavam e participaram do processo de colonização da cidade, elas eram levadas às ruas para se apresentar em desfiles cívicos, em apresentações culturais, outras trabalhavam para ajudar a família. Além disso, eram nas crianças que a esperança de futuro estava também depositada.

Entretanto, a percepção apresentada pela história local é de que as crianças eram figurantes de uma história, de uma sociedade, e não coautoras, produtoras de cultura e da própria história. Não há uma visibilidade justa da infância enquanto sujeitos participantes de todo um processo de constituição de uma cidade. É neste sentido, que os trabalhos que estão sendo realizados no processo dessa pesquisa se fazem de grande importância na tentativa de ampliar as discussões sobre a produção cultural da infância, subsidiando desta forma e dando suporte à História da Infância, uma vez que muito já se tem produzido na contemporaneidade nos campos da Sociologia e na Filosofia da infância, entretanto, na História ainda faz-se necessário expandir tal abordagem, de modo a concebermos a infância como categoria central da história, tratando-a como sujeito social inserido numa história, pertencente a um grupo social, produtor e produto de sua cultura (ROHDEN, 2019). Tal perspectiva nos proporcionará refletir sobre a história pela forma como concebemos a infância, desconstruindo-a e atribuindo-lhe identidade própria. 
Levando em considerações os estudos de Martins e Zóia (2018), é possível verificar em fotografias do momento do processo de abertura de Rondônia que a criança não deixou de estar presente e de fazer parte em nenhum momento desta trajetória, em todo o processo histórico, até mesmo junto aos integrantes da Comissão Rondon, ainda no início do século XIX como mostra a imagem a seguir:

Figura 2: Parte da Comissão Rondon, igro.

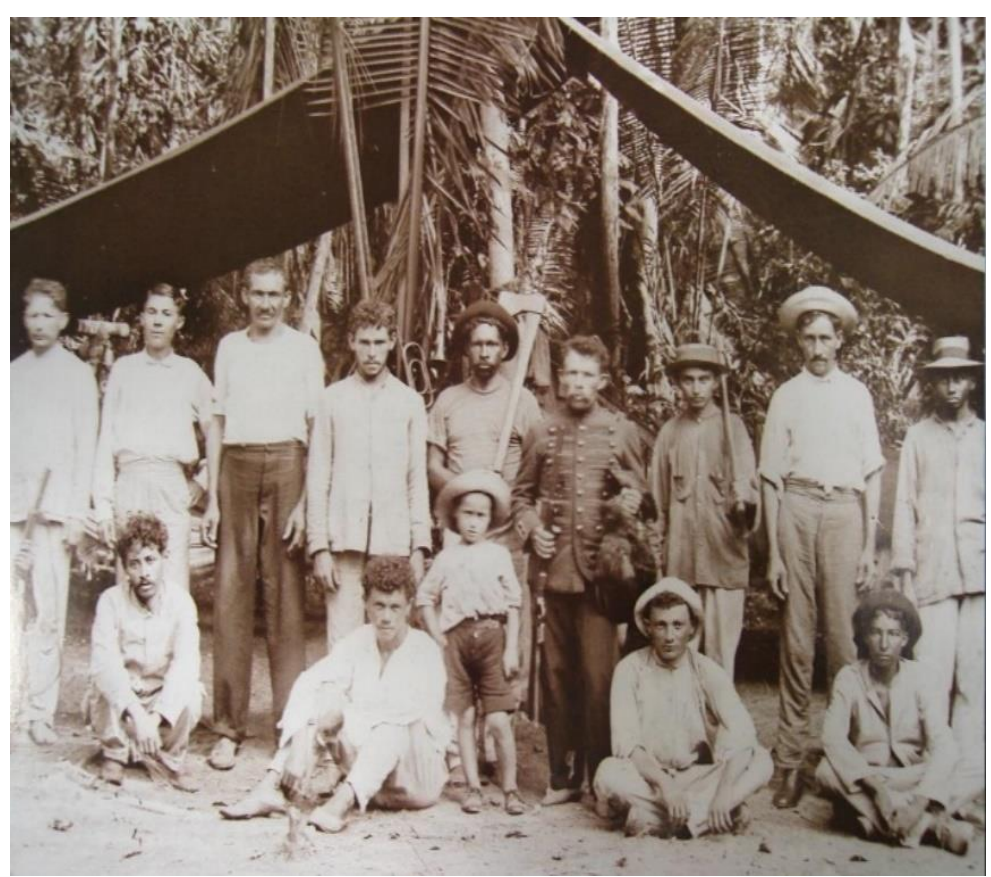

Fonte: Site Rondônia em Sala (2020).

Em todo os movimentos históricos, sabe-se da presença das crianças, porém, elas não possuem um devido reconhecimento como parte da história. Também, se percebe que em muitos momentos contados pela História Oficial, os registros da infância que aparecem em sua maioria, fazem menção à infância branca e sulista, como se não houvesse crianças negras ou pardas, ou mesmo as crianças indígenas, que sabemos que era a infância originária na região amazônica.

Os poucos registros históricos da participação da infância no processo de colonização de Vilhena estão geralmente ligados às datas cívicas, quando as crianças eram levadas às ruas para participar de desfiles cívicos que a escola promovia. Não estamos dizendo que esses registros não são importantes, ao contrário, compreendemos nos mesmos os vestígios da infância em tal sociedade, verificamos diversas possibilidades das práticas, da cultura produzida, entretanto, queremos também saber das crianças negras, da presença e da participação de todas as crianças nesse processo histórico. A figura abaixo relaciona-se ao que estamos argumentando" 
Figura 3: Desfile cívico em Vilhena exaltando à cultura branca e enaltecendo o Sul do país, 1977:

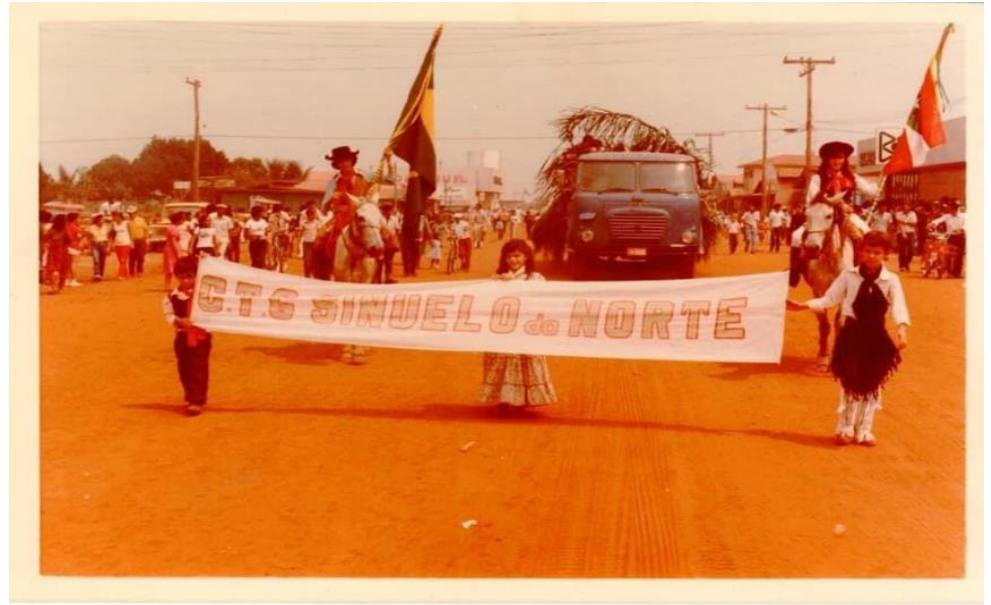

Fonte: Perfil em Rede Social "Memória Vilhenense” (2020).

Nesse contexto, temos como primeiros vestígios da infância negra na história de Vilhena, apenas alguns registros fotográficos que nos mostram também a presença de crianças pardas e negras. Tais imagens não são vinculadas à História Oficial, visto que há claramente a intenção de apresentar uma história do sulista que deixou sua terra de origem e recriou outro "sul" culturalmente falando, em plena região amazônica. O discurso da história de Vilhena é marcado fortemente pela ideologia do "progresso", pela ocupação do sul em solo amazônico, desconsiderando o processo de miscigenação, desconsiderando a vinda do povo nordestino que também deixou sua terra natal na mesma temporalidade em estudo para trabalhar e viver em solo Vilhenense. No entanto, as primeiras impressões da pesquisa nos mostram a presença da criança negra na história de Vilhena especialmente em abrigo infantil, como exemplo, o abrigo Lar da Criança.

Figura 4: Crianças negras, pardas e brancas em Vilhena, década de 1980.

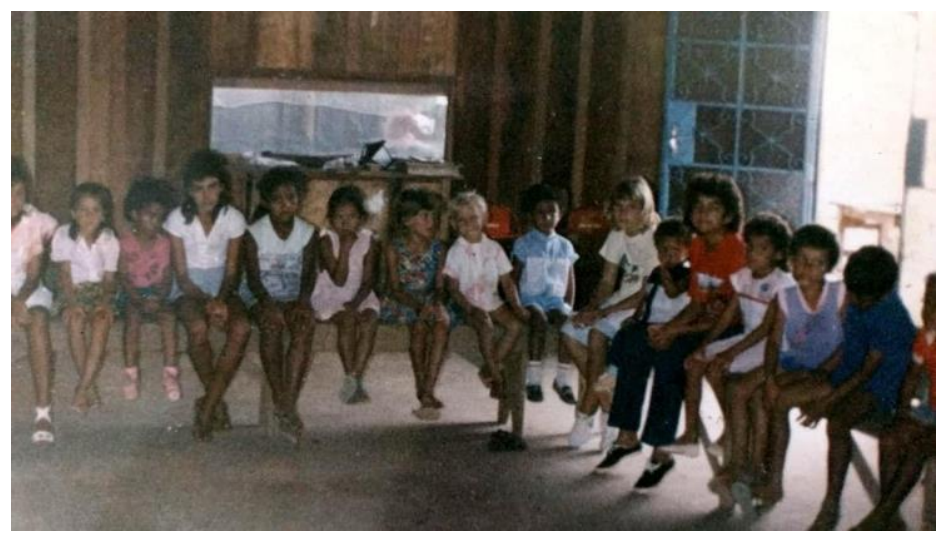

Fonte: Perfil em Rede Social “Memória Vilhenense” (2020). 
Figura 5: Crianças do Abrigo Infantil Lar das Crianças, década de 1980

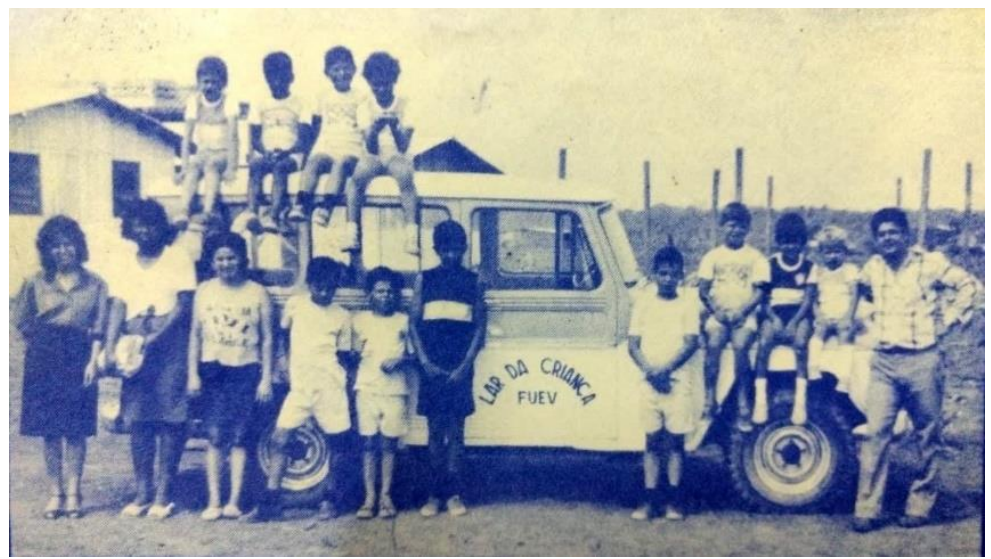

Fonte: Perfil em Rede Social "Memória Vilhenense” (2020).

Figura 6: Crianças do Abrigo Infantil Lar das Crianças, década de I980

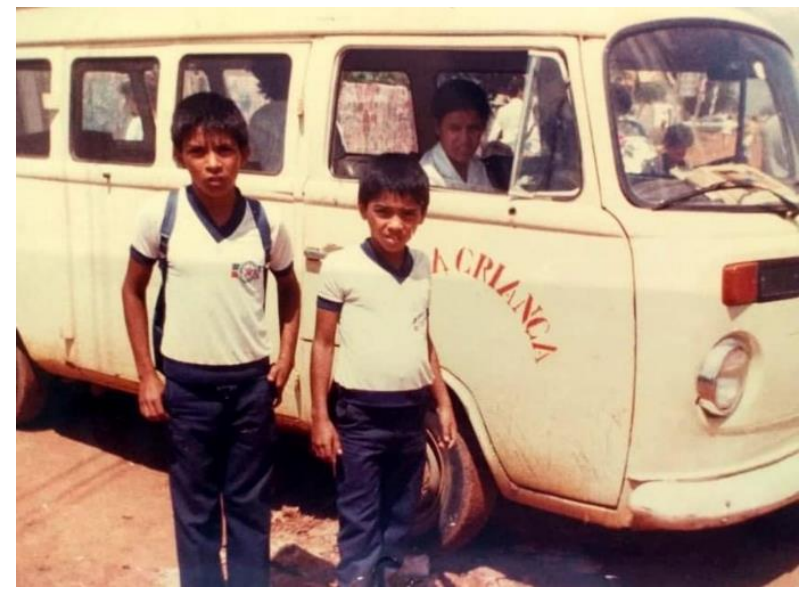

Fonte: Perfil em Rede Social "Memória Vilhenense” (2020).

Diante disso, queremos enfatizar a presença da criança negra na história de Vilhena, por enquanto os primeiros indícios da pesquisa nos fazem tecer possibilidades futuras de uma discussão que envolvem à invisibilidade da participação negra na sociedade que se formava, ou mesmo está relacionada às infâncias mais pobres, crianças no trabalho, muitas sem famílias em processos de adoção, como no caso das imagens históricas encontradas do Abrigo Infantil.

Assim, pesquisar a infância, a criança negra no processo de colonização de Vilhena, apresentase como um grande desafio, em especial compreender todo o cenário migratório, investigar a trajetória educacional e o reflexo que a mesma apresentava sobre a infância e suas representações. 


\section{${ }_{4}$ Considerações finais e/ou conclusões}

Este trabalho intentou apresentar os primeiros indícios da história da infância de Vilhena com um olhar especial para a presença da criança negra, na busca de tecer os debates iniciais e necessários às culturas infantis que contribua para com os estudos no campo da educação, para com as experiências formativas na vida das crianças, ampliando e (re) significando o debate sobre a História da Infância.

Objetivamos a partir dos registros iniciais coletados, verificar a participação da criança negra numa sociedade que se formava branca, numa educação feita pelos e para os brancos e extremamente excludente.

A partir das discussões sobre o processo de colonização do estado de Rondônia, o fluxo migratório de pessoas vindas das regiões sul e nordestina, compreendemos que a história oficial pontua principalmente a presença de uma cultura sulista, branca, não considerando todos que compuseram tal processo histórico. Nesse âmbito, temos uma miscigenação clara, onde brancos, negros, pardos, se juntavam às etnias originais que na região já habitavam. Entretanto, pouco dos que não são brancos aparecem na história. Além disso, as crianças que por si só ocupavam um olhar de figurantes da história, se restringem ainda mais os registros de suas presenças quando essas são negras.

Nesse cenário, este trabalho propõe debater tal ideia no que se diz respeito, em especial, à presença infantil negra, a cultura produzida presentes no cotidiano da história de Vilhena. Desejamos fomentar a visibilidade infantil negra, com vistas às possibilidades de reescrever uma história, desmistificando um passado branco e excludente.

\section{Referências}

BENJAMIN, Walter. Magia e Técnica, arte e política: Ensaios sobre Literatura e História da Cultura. Obras Escolhidas V. I. Trad. Sérgio Paulo Rouanet. 3.‥ ed. São Paulo: Brasiliense, 1987.

BRASIL, Pedro. Vilhena conta sua História. Vilhena: Gráfica Delta, 2000.

CERTEAU, Michel de. A Escrita da História. Tradução de: Maria de Lourdes Menezes, Rio de Janeiro: Forense-Universitária, 1982.

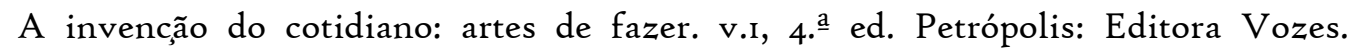
Tradução de Ephraim Ferreira Alves, 1998.

GOMES, E. História e Geografia Rondônia. Vilhena: Gráfica e Editora Express, 2012. 
MARTINS, Helen Arantes. Os modos de lembrar e contar: memórias de uma escola no Município de Vilhena/RO (1960-1980). Cáceres: PPGedu/UNEMAT, 2017. Dissertação de Mestrado.

MARTINS, Helen Arantes; ZÓIA, Alceu. Memórias (Auto)Biográficas de Infâncias: os Vestígios da escolarização no município de Vilhena/RO (1960-1980). Revista Brasileira de Pesquisa (Auto)Biográfica, Salvador, v. 03, n. o8, p. 672-685, maio/ago. 2018. Disponível em: https://www.researchgate.net/publication/32815610I_Memorias_autobiograficas_de_infancias_os_v estigios_da_migracao_e_da_educacao_no_municipio_de_Vilhena-RO_1960-98o Acesso em 20 de set. de 2020.

PERDIGÃO, F.; BASSEGIO, L. Migrantes amazônicos. São Paulo: Loyola, 1992.

ROHDEN, Josiane Brolo; MARTINS, Helen Arantes. Vestígios da história da educação de Vilhena-RO: revisitando a primeira instituição escolar "Wilson Camargo" (1960-1980) Rev. Educa, Porto Velho (RO), v.I, n.2, p. 52 - 69, 2014. Disponível em: https://www.periodicos.unir.br/index.php/EDUCA/article/view/I191/1272 Acesso em 20 set. de 2020.

ROHDEN, Josiane Brolo. Memórias Crianceiras e seus despropósitos: uma investigação históricopoética do brincar-bricoleur de meninos e meninas do/no m/Mato. Tese (Doutorado em Educação). Universidade Federal de Mato Grosso, UFMT: Programa de Pós-Graduação em Educação, PPGE. Cuiabá:UFMT, 2019. 